\title{
Medications Development for Opioid Abuse
}

\author{
S. Stevens Negus and Matthew L. Banks \\ Department of Pharmacology and Toxicology, Virginia Commonwealth University, Richmond, Virginia 23298 \\ Correspondence: ssnegus@vcu.edu
}

Here we describe methods for preclinical evaluation of candidate medications to treat opioid abuse and dependence. Our perspective is founded on the propositions that (1) drug selfadministration procedures provide the most direct method for assessment of medication effects, (2) procedures that assess choice between opioid and nondrug reinforcers are especially useful, and (3) the states of opioid dependence and withdrawal profoundly influence both opioid reinforcement and the effects of candidate medications. Effects of opioid medications on opioid choice in nondependent and opioid-dependent subjects are reviewed. Various nonopioid medications have also been examined, but none yet have been identified that safely and reliably reduce opioid choice. Future research will focus on (1) strategies for increasing safety and/or effectiveness of opioid medications, and (2) continued development of nonopioids such as inhibitors of endocannabinoid catabolic enzymes or inhibitors of opioid-induced glial activation.

$\mathrm{O}$ pioid abuse is a significant public health problem most commonly associated with the illicit opioid heroin but dominated by the recent epidemic in prescription opioid analgesic abuse (Manchikanti and Singh 2008; SAMHSA 2011). Currently approved pharmacotherapies for opioid abuse include an array of opioid receptor ligands (naltrexone, buprenorphine, and methadone) as well as medications for the symptomatic relief of some opioid withdrawal signs (e.g., the $\alpha 2$-adrenergic agonist clonidine) (Gonzalez et al. 2004). However, use of these medications is constrained by a variety of factors that include poor compliance with opioid antagonists, abuse liability of opioid agonists, and limitations in efficacy to prevent relapse with symptomatic treatments like clonidine. In view of the scope of opioid abuse and the constraints on use of existing treatments, the development of new, safer, and more effective medications remains a priority in drug abuse research. Here we will focus on preclinical methods used in medications development for opioid abuse, and our perspective is founded on three related propositions:

1. Drug self-administration procedures provide the most direct measure of abuse-related reinforcing effects of opioids and the most important experimental tool for evaluation of candidate medications.

2. Drug choice procedures constitute a subset of drug self-administration procedures in which subjects choose between drug and nondrug reinforcers, and these choice

Editors: R. Christopher Pierce and Paul J. Kenny

Additional Perspectives on Addiction available at www.perspectivesinmedicine.org

Copyright (C) 2013 Cold Spring Harbor Laboratory Press; all rights reserved; doi: 10.1101/cshperspect.a012104

Cite this article as Cold Spring Harb Perspect Med 2013;3:a012088 
procedures may be especially useful in evaluation of medications for opioid abuse.

3. States of opioid dependence and withdrawal are key determinants of both opioid self-administration and of medication effects on opioid self-administration.

The remainder of this work will briefly discuss evidence for each of these propositions before proceeding to a review of medication effects on opioid choice under various conditions of opioid dependence and withdrawal. We conclude with a consideration of future directions.

\section{EXPERIMENTAL STRATEGIES FOR MEDICATION DEVELOPMENT}

Drug abuse is a disease of behavior characterized by excessive drug choice (Heyman 2009). The primary goal of treatment is to reduce drug use and reallocate behavior to more adaptive activities. Determinants of drug-taking behavior can be directly studied in the laboratory using drug self-administration procedures. In these procedures, delivery of a drug dose (e.g., an intravenous dose of heroin) to an experimental subject (e.g., a rat, nonhuman primate, or human) is made contingent on the performance of some behavior (e.g., pressing an operant response lever) (Young and Herling 1986; Katz 1989; Caine et al. 1999). Under these general conditions, common drugs of abuse typically maintain rates of responding above those maintained by vehicle, and drug self-administration procedures have been used for decades to predict the abuse liability of opioids and other drugs (Johanson and Balster 1978; Ator and Griffiths 2003; O’Connor et al. 2011).

Drug self-administration procedures have also been used to evaluate candidate medications for the treatment of drug abuse (Mello and Negus 1996; Haney and Spealman 2008). In these types of studies, self-administration of the target drug of abuse is established, and candidate medications are screened for their ability to decrease drug self-administration. These experiments are guided by the general premise that medications that decrease preclinical drug self-administration are more likely to serve as promising addiction treatments than medications that do not alter or that increase drug self-administration. However, interpretation of these experiments can be complicated by at least two factors. First, candidate medications can reduce drug self-administration not only by producing a selective and therapeutically useful blockade of drug detection and reinforcement, but also by producing nonselective and undesirable effects (e.g., sedation, paralysis, or cognitive dysfunction) that impair a subject's ability to emit operant responses required for drug self-administration. Because of this potential confound, the mere demonstration that a candidate medication decreases drug self-administration is not sufficient to recommend that medication as a treatment, and several strategies have been developed to address this confound (Mello and Negus 1996). One of these strategies is to study medication effects on drug self-administration in the context of a choice between the target drug of abuse and a nondrug reinforcer such as food (Negus and Banks 2011). For example, Figure 1 shows choice between heroin and food in a group of rhesus monkeys (Negus 2006). In this procedure, daily experimental sessions consisted of five sequential components, and during each component, subjects could respond either on a "heroin-associated" key to earn the available unit dose of heroin (0$0.1 \mathrm{mg} / \mathrm{kg}$ per injection IV) or on a separate "food-associated" key to earn a $1 \mathrm{mg}$ bananaflavored food pellet. Monkeys could complete up to 10 total choices during each component. The top panel of Figure 1 shows the percent of choices completed on the heroin- or food-associated keys, and the bottom panel shows the total number of choices completed on both keys. When " 0 " heroin (no injection) or the low dose of $0.0032 \mathrm{mg} / \mathrm{kg}$ per injection heroin was available, monkeys allocated their responding exclusively toward food choice and earned all 10 available reinforcers. However, higher doses of $0.01-0.1 \mathrm{mg} / \mathrm{kg}$ per injection heroin maintained a dose-dependent reallocation of behavior toward heroin choice. Heroin choice was also associated with a dose-dependent decrease in the total number of choices completed, perhaps 


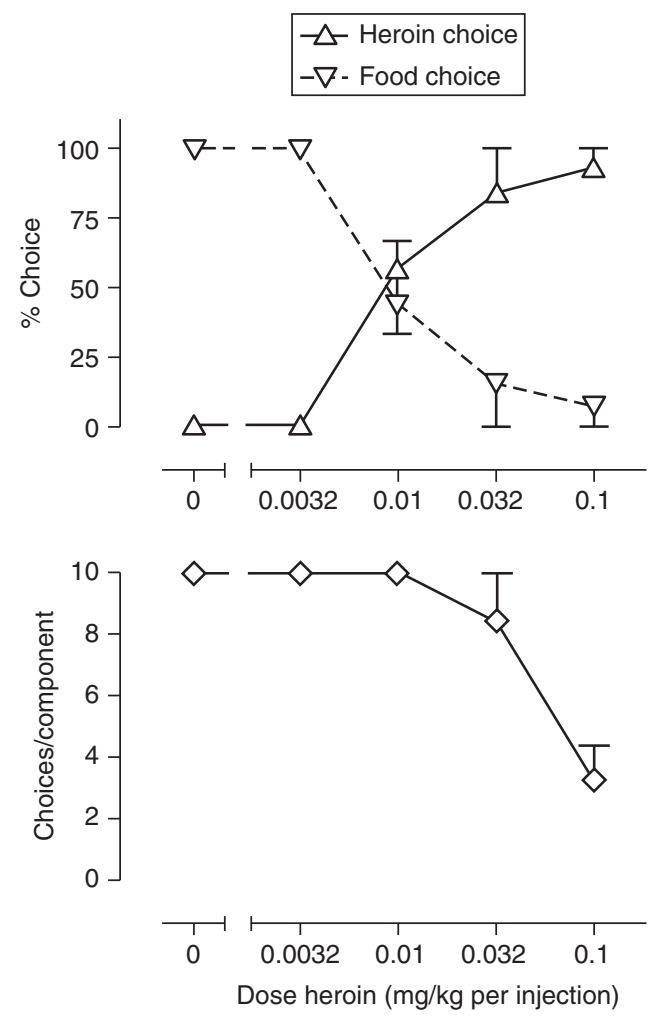

Figure 1. Dose-dependent choice between heroin and food pellets in rhesus monkeys (abscissa: unit dose of heroin available during components of daily choice sessions). Top ordinate: percent of completed choices allocated to the heroin or food options. Bottom ordinate: total number of choices completed for both options. All points show mean \pm SEM for three monkeys. Heroin maintained a dose-dependent increase in heroin choice. (From Negus 2006; adapted, with permission, from the author.)

reflecting the sedative effects of high self-administered heroin doses. Overall, then, choice procedures such as this one yield dependent measures of both reinforcement allocation (\% drug choice) and reinforcement rate (total choices per component), and these two different dependent measures can be used to dissociate beneficial medication effects on drug reinforcement from nonselective and undesirable medication effects that might compromise a subject's ability to respond (Negus and Banks 2011). Specifically, as will be discussed below, changes in drug reinforcement manifest as changes in drug choice,
Medications Development for Opioid Abuse

whereas undesirable effects that impair responding manifest as decreases in reinforcement rate. An ideal medication in this procedure might be one that decreased heroin choice, increased food choice, and produced right shifts in the heroin choice dose-effect curve without reducing reinforcement rate. Preclinical choice procedures have the additional advantages of both mimicking choice procedures used in human laboratory studies and modeling pathological choice of drug over other commodities in clinical drug abuse (Haney and Spealman 2008; Heyman 2009).

A second critical factor that influences both the reinforcing effects of opioid agonists and the impact of candidate medications is the degree of opioid dependence and withdrawal. For example, Figure 2 shows heroin versus food choice dose-effect curves in rhesus monkeys under conditions of nondependence, maintained opioid dependence, and opioid withdrawal (Negus 2006). In the "nondependent" condition, subjects had limited access to heroin only during

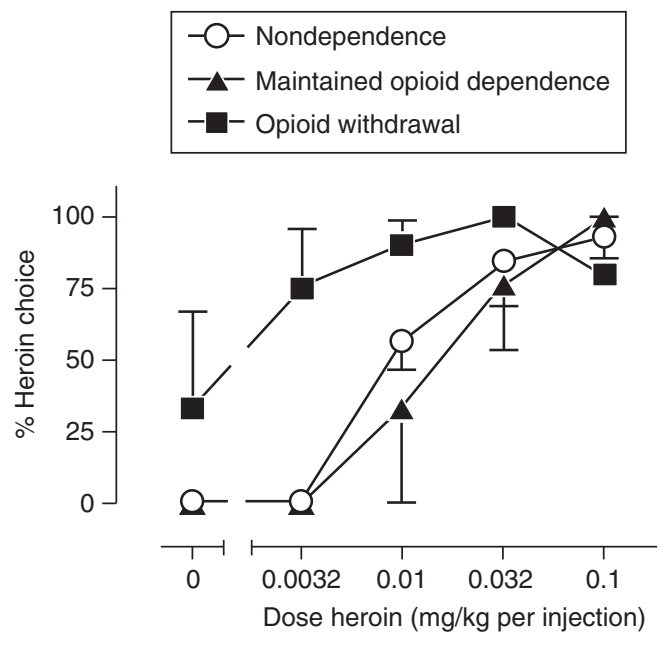

Figure 2. Effects of maintained opioid dependence and withdrawal on heroin choice in rhesus monkeys (abscissa: unit dose heroin; ordinate: percent of completed choices allocated to heroin). All points show mean \pm SEM for three monkeys. Sustained heroin dependence had little effect on heroin choice, but heroin withdrawal increased heroin choice. (From Negus 2006; reprinted, with permission, from the author.) 
daily 2 -h behavioral sessions, and daily heroin consumption was $0.6 \pm 0.2 \mathrm{mg} / \mathrm{kg}$ per day. This relatively small degree of opioid exposure was not sufficient to produce notable opioid dependence in that somatic opioid withdrawal signs were not apparent between choice sessions or if choice sessions were omitted. In the "maintained opioid dependence" condition, heroin intake during choice sessions was supplemented by additional heroin intake during the rest of each experimental day. Specifically, monkeys continued to choose between heroin and food during daily $2 \mathrm{~h}$ choice sessions, but they also had the opportunity to self-administer additional doses of $0.1 \mathrm{mg} / \mathrm{kg}$ per injection heroin every $15 \mathrm{~min}$ for the $22 \mathrm{~h}$ between daily choice sessions. In this context of augmented heroin access, daily heroin consumption increased approximately eightfold to $5.0 \pm$ $0.3 \mathrm{mg} / \mathrm{kg}$ per day heroin. So long as this augmented degree of heroin access and intake was sustained, there was little change in the heroin choice dose-effect curve. However, when access to supplemental heroin was terminated, monkeys entered a state of spontaneous opioid withdrawal characterized both by the emergence of somatic withdrawal signs (data not shown) and by a dramatic increase in heroin choice manifested as a left shift in the heroin choice doseeffect curve. This increase in heroin choice provides evidence of a withdrawal-associated increase in the relative reinforcing effects of heroin, and this conclusion is consistent with evidence of withdrawal-associated increases in opioid reinforcement under other schedules of reinforcement (Spragg 1940; Thompson and Schuster 1964; Griffiths et al. 1975; Yanagita 1978). This withdrawal-associated increase in opioid reinforcement presents a barrier to abstinence, and as discussed below, medications effects on opioid reinforcement in a nondependent state can differ dramatically from their effects on withdrawal-associated increases in opioid reinforcement in dependent subjects. This difference suggests that strategies for both treatment of opioid abuse and for medications development should be tailored not only to opioids as the target drugs of abuse, but also to the level of opioid dependence.

\section{MEDICATION EFFECTS ON OPIOID CHOICE}

\section{Opioid Medications}

Currently approved medications for the treatment of opioid dependence include the opioid antagonist naltrexone, the intermediate-efficacy opioid agonist buprenorphine, and the highefficacy opioid agonist methadone. Effects of these and related opioids on heroin versus food choice provide a framework of standard outcomes that can be used to assess predictive validity of choice procedures and interpret effects of other compounds. Table 1 summarizes effects of opioid medications on opioid choice in preclinical and human laboratory studies, and illustrative data are discussed below.

\section{Opioid Antagonists}

Figure 3 shows the opposite effects of opioid antagonists on heroin choice in nondependent and opioid-dependent monkeys (Negus 2006, 2009). In nondependent monkeys, the antagonist naloxone delivered by continuous infusion produced dose-dependent rightward shifts in the heroin choice dose-effect curve (i.e., decreased heroin choice), and these doses of naloxone did not reduce the total number of choices completed (data not shown). These findings agree with reductions in heroin versus money choice produced by opioid antagonists in nondependent (postdependent) humans (see references in Table 1), and with the efficacy of opioid antagonists as antirelapse medications in highly motivated postdependent opioid abusers, they are able to maintain compliance with antagonist treatment regimens (Sevarino and Kosten 2007). Conversely, Figure 3 also shows that the antagonist naltrexone produced dosedependent leftward shifts in the heroin choice dose-effect curve (i.e., increased heroin choice) under conditions of maintained opioid dependence. This increase in heroin choice was accompanied by precipitated signs of opioid withdrawal and resembles the withdrawal-associated increase in heroin choice produced by spontaneous heroin withdrawal shown in Figure 2. 
Medications Development for Opioid Abuse

Table 1. Summary of published manuscripts reporting on IV opioid self-administration under concurrent-choice schedules

\begin{tabular}{|c|c|c|c|c|c|}
\hline Drug & $\begin{array}{l}\text { Alternative } \\
\text { reinforcer }\end{array}$ & Species & Dependence & $\begin{array}{l}\text { Main effect } \\
\text { examined }\end{array}$ & References \\
\hline Morphine & Banana & Chimpanzee & Y & Morphine: $\downarrow$ & Spragg 1940 \\
\hline Heroin & Food pellet & Baboon & $\mathrm{Y}$ & $\begin{array}{l}\text { Methadone: } \downarrow \\
\text { Naloxone: } \uparrow\end{array}$ & Griffiths et al. 1975 \\
\hline Heroin & $\begin{array}{l}\text { Food pellet } \\
\pm \text { heroin }\end{array}$ & Baboon & $\mathrm{Y}$ & Morphine: $\downarrow$ & Wurster et al. 1977 \\
\hline Heroin & Food pellet & Baboon & $\mathrm{Y}$ & $\begin{array}{l}\text { Morphine: } \downarrow \\
\text { Naloxone: } \uparrow \\
\text { Secobarbital: —— }\end{array}$ & Griffiths et al. 1981 \\
\hline Heroin & Food pellet & Rhesus & $\mathrm{N}$ & $\begin{array}{l}\text { Methadone: - } \\
\text { Buprenorphine: } \downarrow \\
\text { Naltrexone: } \downarrow \\
\text { Methadone: } \downarrow \\
\text { Buprenorphine: } \uparrow\end{array}$ & Negus 2006 \\
\hline Heroin & Food pellet & Rhesus & $\mathrm{Y}$ & Naltrexone: $\uparrow$ & Negus 2009 \\
\hline Heroin & Food pellet & Rhesus & $\mathrm{Y}$ & $\begin{array}{l}\text { Morphine: } \downarrow \\
\text { Amphetamine: - } \\
\text { Clonidine: - } \\
\text { Antalarmin: - } \\
\text { 5'-Guanidinonal- } \\
\quad \text { trindole: - }\end{array}$ & Negus and Rice 2009 \\
\hline Heroin & $\begin{array}{l}\text { Brain } \\
\text { stimulation }\end{array}$ & Rat & $\mathrm{N}$ & Naloxone: $\downarrow$ both & Gerber et al. 1985 \\
\hline Heroin & Money & Human & $\mathrm{PD}$ & $\begin{array}{c}\text { Buprenorphine/ } \\
\text { naloxone: } \downarrow\end{array}$ & Comer et al. 2005 \\
\hline Heroin & Money & Human & PD & Buprenorphine: $\downarrow$ & Comer et al. 2001 \\
\hline Heroin & Money & Human & $\mathrm{PD}$ & Buprenorphine: $\downarrow$ & Mello et al. 1982 \\
\hline Heroin & Money & Human & $\mathrm{PD}$ & Depot naltrexone: $\downarrow$ & Sullivan et al. 2006 \\
\hline Hydromorphone & Money & Human & $\mathrm{PD}$ & Buprenorphine: $\downarrow$ & Greenwald et al. 2002 \\
\hline Hydromorphone & Money & Human & $\mathrm{PD}$ & $\begin{array}{l}\text { Postsession drug } \\
\text { availability: - }\end{array}$ & $\begin{array}{l}\text { Greenwald and } \\
\text { Steinmiller } 2009\end{array}$ \\
\hline Hydromorphone & Money & Human & PD & $\begin{array}{l}\text { Presession drug } \\
\quad \text { availability: } \downarrow\end{array}$ & $\begin{array}{l}\text { Greenwald and Hursh } \\
\quad 2006\end{array}$ \\
\hline
\end{tabular}

Columns show the primary drug option(s); the alternative reinforcer(s) (sometimes also a drug); the species in which studies were conducted; whether the subjects were opioid dependent $(\mathrm{Y})$, not $(\mathrm{N})$, or postdependent $(\mathrm{PD})$; the primary effect examined in the study and the main effect on drug choice (down arrow, decreased opioid choice; up arrow, increased opioid choice; dash, no change in opioid choice); and the references.

Effects of opioid antagonists on withdrawal-associated increases in opioid choice have not been examined, but the expected effects would be either no effect or an exacerbation of these increases in opioid choice. The ability of opioid antagonists to precipitate somatic withdrawal signs and withdrawal-associated increases in opioid reinforcement likely contributes to poor compliance with antagonist treatments (Negus 2009).

\section{Buprenorphine}

Buprenorphine produces effects on opioid choice that are intermediate between those of antagonists or agonists. Thus, in nondependent monkeys or postdependent humans, buprenorphine maintenance produces a dose-dependent and antagonist-like decrease in opioid choice ( Table 1). However, unlike antagonists, termination of 5-d buprenorphine treatment in originally 
S.S. Negus and M.L. Banks
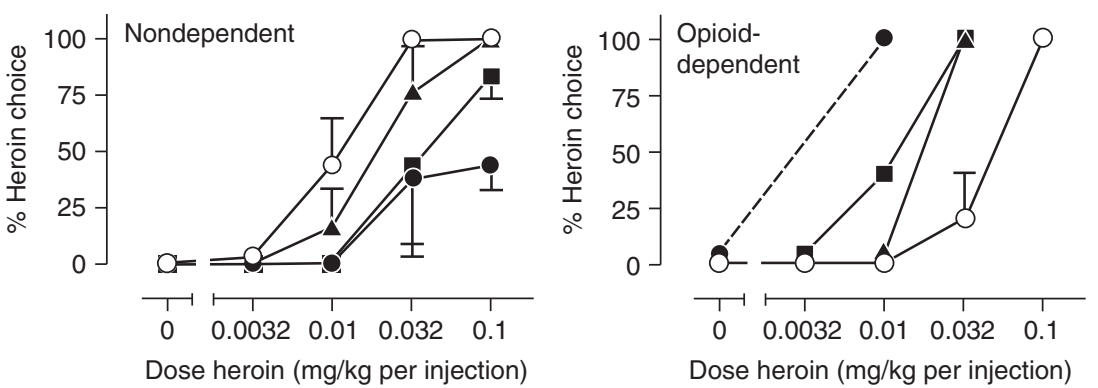

Figure 3. Effects of opioid antagonists on heroin choice in two nondependent rhesus monkeys (left panel) and one heroin-dependent rhesus monkey (right panel). Other details as in Figure 2. Naltrexone produced opposite effects on heroin choice depending on the state of heroin dependence. (From Negus 2009; reprinted, with permission, from the author.)

nondependent monkeys produced both the emergence of mild somatic withdrawal signs and a withdrawal-associated increase in opioid choice (Negus 2006). These findings suggest that buprenorphine treatment regimens sufficient to reduce choice of a relatively high-efficacy opioid like heroin may also produce a relatively mild form of opioid dependence. This finding is consistent with other evidence to suggest that buprenorphine can function as a weak agonist capable of producing opioid dependence, and this dependence liability poses a risk in the use of buprenorphine as a maintenance medication in nondependent (postdependent) opioid abusers (Negus and Woods 1995).

The effects of buprenorphine on opioid choice have not been systematically examined under states of maintained opioid dependence except insofar as that dependence was maintained by buprenorphine itself as discussed above. Under these conditions of mild, buprenorphine-induced dependence, buprenorphine maintenance produced a sustained decrease in heroin choice and a blockade of buprenorphine withdrawal-associated increases in heroin choice (Table 1). However, buprenorphine effects were less consistent in blocking withdrawal-associated increases in heroin choice in monkeys rendered highly opioid dependent via access to supplemental heroin self-administra- tion as shown in Figure 2 (Negus 2006). In heroin-dependent monkeys, buprenorphine reduced withdrawal-associated increases in heroin choice in only one of three monkeys tested, and in the other two monkeys, it either did not affect or exacerbated withdrawal-associated increases in heroin choice. Taken together, these results suggest that buprenorphine can decrease choice of higher efficacy opioids like heroin in nondependent or mildly dependent states, but the effectiveness of buprenorphine diminishes as the intensity of opioid dependence increases.

\section{Opioid Agonists}

Higher efficacy opioid agonists such as morphine and methadone have little effect on opioid choice in nondependent subjects. An example of this phenomenon was shown above in Figure 2, wherein self-administration of supplemental heroin between heroin choice sessions had little effect on heroin choice during choice sessions in rhesus monkeys. Similar results are obtained with noncontingent maintenance on agonists like methadone (Negus 2006). However, as shown in Figure 2 or described above with buprenorphine, maintenance on opioid agonists will establish opioid dependence in originally nondependent subjects, and once this dependence is established, then termination of 
agonist elicits both somatic withdrawal signs and withdrawal-associated increases in opioid choice. As with buprenorphine, this dependence liability poses a risk to the use of agonist medications to treatment of nondependent (postdependent) opioid abusers.

Once opioid dependence is established, however, opioid agonists can block withdrawal-associated increases in opioid choice and liberate subjects to engage in behaviors maintained by nonopioid reinforcers (Table 1 ). For example, Figure 4 shows effects of morphine on heroin versus food choice in heroin-dependent rhesus monkeys. Experiments shown in this graph were conducted using the same choice procedure as described above to examine heroin choice doseeffect curves, but for the sake of simplifying data presentation, this graph shows the total percent of heroin choice across all heroin doses (Negus and Rice 2009). Under baseline (BL) conditions, monkeys had access to supplemental heroin between choice sessions, and during choice sessions, the subjects allocated $\sim 30 \%$ of their total choices to heroin (at the high heroin doses) and the remainder of their choices to food (at the lower heroin doses). Spontaneous withdrawal (WD) was introduced by terminating access to supplemental heroin for 1 day. Withdrawal elicited the emergence of both somatic withdrawal signs and a withdrawal-associated increase in heroin choice. Morphine administered during the period of heroin withdrawal produced a dose-dependent blockade of both somatic with- drawal signs and of the withdrawal-associated increase in heroin choice. We have argued that the efficacy of opioid agonists to block withdrawal-associated increases in opioid choice contributes both to continued opioid use by dependent subjects and to the efficacy of opioid agonists as maintenance medications to decrease illicit opioid use.

\section{Summary and Implications for Medications Development}

Figure 5 summarizes key points from research on the efficacy of opioid medications to modulate opioid choice. Opioid use can be conceptualized as occurring in subjects that migrate along a continuum from nondependent to varying degrees of opioid dependence and back to postdependent. As subjects range up and down this continuum of opioid dependence, therapeutic efficacy to reduce opioid use is best achieved with a matching continuum of medications that progress from the opioid antagonist naltrexone in nondependent/postdependent subjects to the intermediate-efficacy agonist buprenorphine in modestly dependent subjects to the high-efficacy agonist methadone in highly dependent subjects. Moreover, the impact of medications on opioid choice also varies along this continuum. Opioid antagonists like naltrexone block opioid choice in nondependent/postdependent subjects, whereas opioid agonists like buprenorphine and methadone

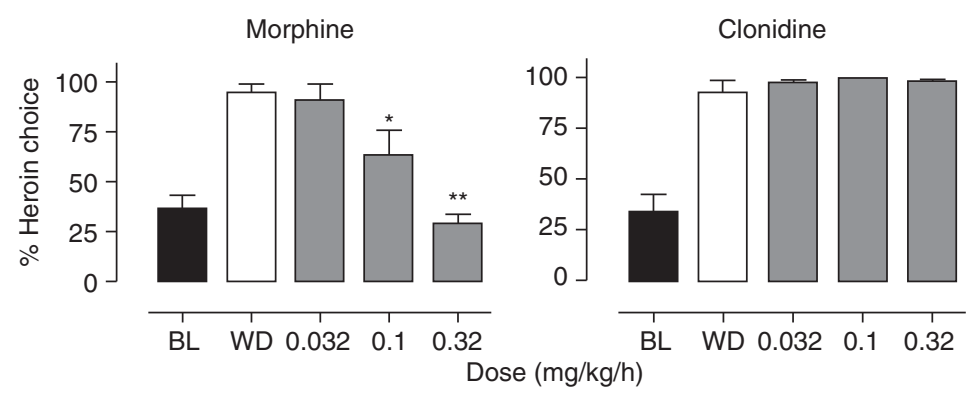

Figure 4. Effects of morphine and clonidine on withdrawal-associated increases in heroin choice (abscissa: dose morphine or clonidine in $\mathrm{mg} / \mathrm{kg} / \mathrm{h}$; ordinate: percent of choices allocated to heroin across all heroin doses). Morphine dose-dependently blocked withdrawal-associated increases in heroin choice, whereas clonidine did not up the doses that produced overt sedation. (From Negus and Rice 2009; reprinted, with permission, from the authors.) 
S.S. Negus and M.L. Banks

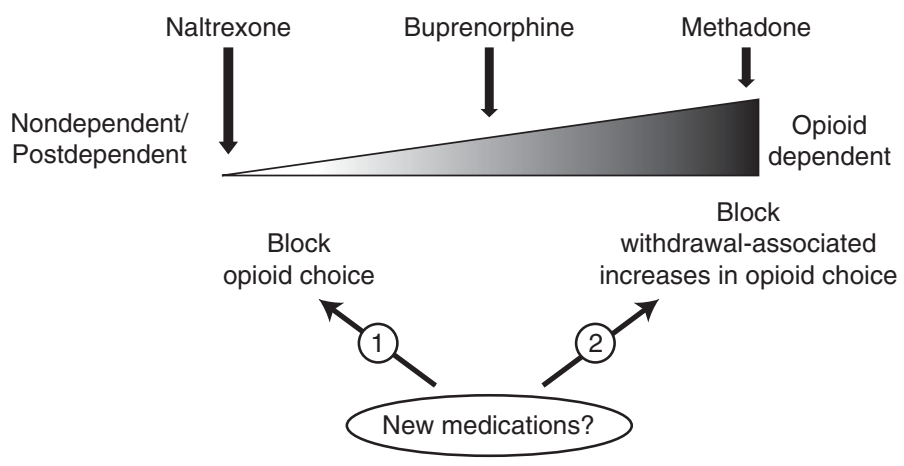

Figure 5. Schematic showing the clinical effectiveness of opioid medications under different states of opioid dependence. New medications could be evaluated for their ability to (1) block opioid choice in nondependent subjects, or (2) block withdrawal-associated increases in opioid choice in dependent subjects.

block withdrawal-associated increases in opioid reinforcement in modestly and highly dependent subjects, respectively.

This array of medications permits a flexible and relatively effective approach to the management of opioid abuse. However, as noted above, use of these opioid medications is complicated by factors that include low compliance with antagonists and abuse liability of agonists. Medications development seeks new strategies either (a) to improve opioid medications, or (b) to develop nonopioid medications that are safer and/or more efficacious than opioid medications. Regarding the first of these strategies, the chief challenge with opioid antagonists has been compliance with medication regimens, and strategies to improve compliance include development of long-acting formulations that minimize the required frequency of treatment and hence the opportunities for compliance failure (e.g., long-acting formulations of naltrexone) (Comer et al. 2007; Sevarino and Kosten 2007). Conversely, with opioid agonist medications, strategies to reduce abuse liability include development of agonist/antagonist formulations designed to retard abuse by parenteral routes of administration while protecting effectiveness obtained via intended enteral routes of administration (e.g., Suboxone, a mixture of buprenorphine and the opioid antagonist naloxone) (Comer et al. 2005; Sevarino and Kosten 2007). These efforts to improve existing opioid medications will not be considered further here, and the remainder of this work will focus on efforts to develop nonopioid medications for the treatment of opioid abuse.

\section{Non- $\mu$ Opioid Medications}

The addictive effects of abused opioids are mediated most proximally by their actions on $\mu$ opioid receptors, and opioid medications function by interacting directly with these proximal receptor targets. However, abused opioids also indirectly engage other downstream systems of intra- and intercellular signaling, and modulation of these downstream mechanisms may also produce therapeutically useful effects together with profiles of side effects that are different from, and perhaps safer than, those of $\mu$ opioid medications. Research to investigate effects of non- $\mu$ opioids on opioid choice (in nondependent/postdependent subjects) or on withdrawal-associated increases in opioid choice (in dependent subjects) is just beginning, and Table 1 summarizes the largely disappointing results of studies conducted so far. The most clinically relevant of these drugs is clonidine, an $\alpha 2$ adrenergic receptor antagonist approved for use in managing sympathomimetic signs of opioid withdrawal (Gold et al. 1979; Jasinski et al. 1985). However, despite the effectiveness of clonidine to reduce some withdrawal signs, Figure 4 shows that clonidine failed to block withdrawal-associated increases in heroin choice in rhesus monkeys, and this agrees with the poor 
efficacy of clonidine to prevent relapse in opioid abusers (Negus and Rice 2009).

Noradrenergic systems constitute only one of several neurochemical systems that become hyperactive during opioid withdrawal. Systems that use corticotropin-releasing hormone $(\mathrm{CRH})$ and the endogenous $\mathrm{\kappa}$-selective opioid agonist dynorphin also are up-regulated during opioid use and withdrawal (Wee and Koob 2010; Logrip et al. 2011). This has led to speculation that $\mathrm{CRH}$ and/or dynorphin might mediate some signs of withdrawal, and that antagonists of $\mathrm{CRH}$ or $\kappa$-opioid receptors might attenuate withdrawal. However, the CRH-1 receptor antagonist antalarmin did not reliably block withdrawal-associated increases in heroin choice in heroin-dependent monkeys, and the $\kappa$ opioid receptor antagonist $5^{\prime}$-guanidinonaltrindole exacerbated withdrawal-associated increases in heroin choice (Negus and Rice 2009). Lastly, opioid withdrawal is also associated with decreases in activity of some neurobiological systems, and given the well-established importance of the mesolimbic dopamine system as a mediator of motivated behavior, withdrawal-associated decreases in mesolimbic dopamine release may play an especially important role in modulating drug self-administration and the allocation of choice between drug and nondrug reinforcers (He et al. 2004). In accordance with a potential role for decreased dopamine in opioid withdrawal, the indirect dopamine agonists amphetamine and cocaine blocked the discriminative stimulus effects of opioid withdrawal in opioid-dependent rhesus monkeys (Sell and France 2002); however, amphetamine failed to reliably decrease withdrawal-associated increases in opioid choice (Negus and Rice 2009).

Taken together, these data argue against an exclusive role for $\alpha 2$ adrenergic agonists, $\mathrm{CRH}-1$ or $\kappa$ opioid receptor antagonists, or indirect dopamine agonists for the treatment of dependent opioid abusers, but much additional research is required to clarify the potential utility of these medications across a more diverse range of clinically relevant conditions. For example, these drugs have been examined at only one, relatively high level of opioid dependence for which buprenorphine was also not reliably effective in blocking withdrawal-associated increases in heroin choice. Further research will be required to determine if these or related medications might be more effective at lower levels of opioid dependence or in postdependent opioid users. Moreover, combinations of these medications may improve clinical effectiveness by targeting multiple systems dysregulated by opioid abuse.

\section{FUTURE DIRECTIONS}

In addition to the mechanisms discussed above, other nonopioid mechanisms are also emerging as potential targets for candidate medications, and two illustrative classes of candidate medications will be discussed here. One emerging class of compounds is constituted by inhibitors of the endocannabinoid hydrolytic enzymes fatty acid amide hydrolase (FAAH) and monoacylglycerol lipase (MAGL). These enzymes are responsible for the metabolism of the major endocannabinoids $\mathrm{N}$-arachidonoylethanolamine (anandamide; AEA) and 2-arachidonylglycerol (2-AG), respectively (Ahn et al. 2008). During naloxoneprecipitated withdrawal, AEA and 2-AG levels in the locus coeruleus, periaqueductal gray and amygdala were not significantly different from vehicle controls or morphine-dependent mice (Ramesh et al. 2011). However, another study reported increased AEA levels in the nucleus accumbens, caudate putamen, hippocampus, and prefrontal cortex, but decreased 2-AG levels in the caudate putamen, hippocampus, and prefrontal cortex 15 days after termination of chronic morphine in rats (Viganò et al. 2004). More research is clearly needed to better understand the effects of different levels of opioid dependence and subsequent withdrawal on central nervous system (CNS) endocannabinoid levels. Direct administration of AEA or 2-AG into the CNS attenuated somatic signs of antagonist-precipitated opioid withdrawal (Vela et al. 1995; Yamaguchi et al. 2001). Furthermore, systemic administration of a FAAH or MGL inhibitor also attenuated the somatic signs of precipitated or spontaneous opioid withdrawal (Del Arco et al. 2002; Ramesh et al. 2011; Shahidi and Hasanein 2011). Moreover, administration of an FAAH inhibitor attenuated precipitated 
opioid withdrawal-induced conditioned place aversion, suggesting that the endocannabinoid system may also be involved in the affective component of opioid withdrawal (Manwell et al. 2009). Overall, these results suggest that further studies examining FAAH or MAGL inhibitors as candidate medications for treating withdrawal-induced increases in opioid choice warrant further consideration.

Another emerging class of compounds being considered as candidate medications for opioid dependence consists of glial modulators. Glia are nonneuronal cells responsible for supporting proliferation and maturation of neurons. Opioid exposure induces glial activation and subsequent release of proinflammatory cytokines (Hutchinson et al. 2007; Watkins et al. 2009). Specifically, chronic opioid exposure has been shown to up-regulate glial-specific markers and increase spinal and brain levels of proinflammatory cytokines such as interlukin$1 \beta$, interleukin- 6 , and tumor necrosis factor- $\alpha$ (Song and Zhao 2001; Raghavendra et al. 2003; Tawfik et al. 2005; Watkins et al. 2009; Liu et al. 2011). Unfortunately, research has not been conducted to examine levels of these proinflammatory cytokines, or other markers of glial activation during spontaneous or precipitated opioid withdrawal. However, administration of glial modulators such as ibudilast, pentoxifylline, propentofylline, minocycline, or $(+)$-naloxone attenuated somatic signs of both spontaneous and precipitated opioid withdrawal in rodents (Raghavendra et al. 2003; Hutchinson et al. 2009, 2010; Mika et al. 2009). These results are consistent with the hypothesis that glial activation and subsequent release of proinflammatory cytokines appears to be involved in the development of opioid dependence and support further research of these compounds on basal opioid choice or withdrawal-induced increases in opioid choice.

\section{CONCLUDING REMARKS}

Opioid abuse remains a public health problem, and development of safe and effective medications remains a priority in drug abuse research. Currently approved opioid medications exist on a continuum of pharmacological efficacy at the $\mu$ opioid receptor and range from the opioid antagonist naltrexone to the intermediate-efficacy agonist buprenorphine and the high-efficacy agonist methadone. The effectiveness of these medications to reduce opioid choice is governed by the state of opioid dependence and withdrawal in the subject being treated. Antagonists reduce opioid choice in nondependent and postdependent subjects, whereas intermediate- and high-efficacy agonists block withdrawal-associated increases in opioid choice in opioid-dependent subjects. However, use of these medications is limited by factors that include poor compliance with antagonists and abuse liability of agonists. A range of nonopioid medications has been evaluated in accordance with hypotheses regarding neural systems that may be pathologically dysregulated by opioid abuse. To date, medications that function as $\alpha 2$ adrenergic agonists, corticotropinreleasing hormone 1 receptor or $\kappa$ opioid receptor antagonists, or indirect dopamine agonists have failed to reliably reduce opioid choice in dependent subjects. However, future research with these agents is warranted, and new agents that target endocannabinoid catabolic enzymes or mechanisms of opioid-induced glial activation are also areas of intense study. Procedures that permit assessment of opioid choice in nondependent subjects and of withdrawal-associated increases in opioid choice in opioid-dependent subjects provide a versatile experimental platform for assessment of emerging candidate medications.

\section{ACKNOWLEDGMENTS}

This work is supported in part by grants R01DA026946 and P01-DA032933 from the National Institutes of Health.

\section{REFERENCES}

Ahn K, McKinney MK, Cravatt BF. 2008. Enzymatic pathways that regulate endocannabinoid signaling in the nervous system. Chem Rev 108: 1687-1707.

Ator NA, Griffiths RR. 2003. Principles of drug abuse liability assessment in laboratory animals. Drug Alcohol Depend 70: S55-S72. 
Caine SB, Negus SS, Mello NK. 1999. Method for training operant responding and evaluating cocaine self-administration behavior in mutant mice. Psychopharmacology 147: $22-24$.

Comer SD, Collins ED, Fischman MW. 2001. Buprenorphine sublingual tablets: Effects on IV heroin self-administration by humans. Psychopharmacology 154: 28-37.

Comer SD, Walker EA, Collins ED. 2005. Buprenorphine/ naloxone reduces the reinforcing and subjective effects of heroin in heroin-dependent volunteers. Psychopharmacology 181: 1-12.

Comer SD, Sullivan MA, Hulse GK. 2007. Sustained-release naltrexone: Novel treatment for opioid dependence. $E x-$ pert Opin Investig Drugs 16: 1285-1294.

Del Arco I, Navarro M, Bilbao A, Ferrer B, Piomelli D, Rodriguez De Fonseca F. 2002. Attenuation of spontaneous opiate withdrawal in mice by the anandamide transport inhibitor am404. Eur J Pharmacol 454: 103-104.

Gerber GJ, Bozarth MA, Spindler JE, Wise RA. 1985. Concurrent heroin self-administration and intracranial selfstimulation in rats. Pharmacol Biochem Behav 23: 837842.

Gold MS, Redmond DEJr, Kleber HD. 1979. Noradrenergic hyperactivity in opiate withdrawal supported by clonidine reversal of opiate withdrawal. Am J Psychiatry 136: $100-102$.

Gonzalez G, Oliveto A, Kosten TR. 2004. Combating opiate dependence: A comparison among the available pharmacological options. Expert Opin Pharmacother 5: 713-725.

Greenwald MK, Hursh SR. 2006. Behavioral economic analysis of opioid consumption in heroin-dependent individuals: Effects of unit price and pre-session drug supply. Drug Alcohol Depend 85: 35-48.

Greenwald MK, Steinmiller CL. 2009. Behavioral economic analysis of opioid consumption in heroin-dependent individuals: Effects of alternative reinforcer magnitude and post-session drug supply. Drug Alcohol Depend 104: 8493.

Greenwald M, Schuh K, Hopper J, Schuster C, Johanson CE. 2002. Effects of buprenorphine sublingual tablet maintenance on opioid drug-seeking behavior by humans. Psychopharmacology 160: 344-352.

Griffiths RR, Wurster RM, Brady JV. 1975. Discrete-trial choice procedure: Effects of naloxone and methadone on choice between food and heroin. Pharmacol Rev 27: 357-365.

Griffiths RR, Wurster RM, Brady JV. 1981. Choice between food and heroin: Effects of morphine, naloxone, and secobarbital. J Exp Anal Behav 35: 335-351.

Haney M, Spealman R. 2008. Controversies in translational research: Drug self-administration. Psychopharmacology 199: 403-419.

He S, Li N, Grasing K. 2004. Long-term opiate effects on amphetamine-induced dopamine release in the nucleus accumbens core and conditioned place preference. Pharmacol Biochem Behav 77: 327-335.

Heyman GM. 2009. Addiction: A disorder of choice. Harvard University Press, Cambridge, MA.

Hutchinson MR, Bland ST, Johnson KW, Rice KC, Maier SF Watkins LR. 2007. Opioid-induced glial activation: Mechanisms of activation and implications for opioid
Medications Development for Opioid Abuse

analgesia, dependence, and reward. Sci World J Sci 7: 98-111.

Hutchinson MR, Lewis SS, Coats BD, Skyba DA, Crysdale NY, Berkelhammer DL, Brzeski A, Northcutt A, Vietz CM, Judd CM, et al. 2009. Reduction of opioid withdrawal and potentiation of acute opioid analgesia by systemic av411 (ibudilast). Brain Behav Immun 23: 240250.

Hutchinson MR, Zhang Y, Shridhar M, Evans JH, Buchanan MM, Zhao TX, Slivka PF, Coats BD, Rezvani N, Wieseler J, et al. 2010. Evidence that opioids may have toll-like receptor 4 and md-2 effects. Brain Behav Immun 24: 83-95.

Jasinski DR, Johnson RE, Kocher TR. 1985. Clonidine in morphine withdrawal. Differential effects on signs and symptoms. Arch Gen Psychiatry 42: 1063-1066.

Johanson CE, Balster RL. 1978. A summary of the results of a drug self-administration study using substitution procedures in rhesus monkeys. Bull Narc 30: 43-54.

Katz JL. 1989. Drugs as reinforcers: Pharmacological and behavioural factors. In The neuropharmacological basis of reward (ed. Liebman JM, Cooper SJ), pp. 164-213. Clarendon, Oxford.

Liu L, Coller JK, Watkins LR, Somogyi AA, Hutchinson MR. 2011. Naloxone-precipitated morphine withdrawal behavior and brain IL-1 $\beta$ expression: Comparison of different mouse strains. Brain Behav Immun 25: 1223-1232.

Logrip ML, Koob GF, Zorrilla EP. 2011. Role of corticotropin-releasing factor in drug addiction: Potential for pharmacological intervention. CNS Drugs 25: 271-287.

Manchikanti L, Singh A. 2008. Therapeutic opioids: A tenyear perspective on the complexities and complications of the escalating use, abuse, and nonmedical use of opioids. Pain Phys 11: S63-S88.

Manwell LA, Satvat E, Lang ST, Allen CP, Leri F, Parker LA. 2009. Faah inhibitor, URB-597, promotes extinction and CB1 antagonist, SR141716, inhibits extinction of conditioned aversion produced by naloxone-precipitated morphine withdrawal, but not extinction of conditioned preference produced by morphine in rats. Pharmacol Biochem Behav 94: 154-162.

Mello NK, Negus SS. 1996. Preclinical evaluation of pharmacotherapies for treatment of cocaine and opioid abuse using drug self-administration procedures. Neuropsychopharmacology 14: 375-424.

Mello NK, Mendelson JH, Kuehnle JC. 1982. Buprenorphine effects on human heroin self-administration: An operant analysis. J Pharmacol Exp Ther 223: 30-39.

Mika J, Wawrzczak-Bargiela A, Osikowicz M, Makuch W, Przewlocka B. 2009. Attenuation of morphine tolerance by minocycline and pentoxifylline in naive and neuropathic mice. Brain Behav Immun 23: 75-84.

Negus SS. 2006. Choice between heroin and food in nondependent and heroin-dependent rhesus monkeys: Effects of naloxone, buprenorphine, and methadone. J Pharmacol Exp Ther 317: 711-723.

Negus SS. 2009. Opioid antagonist effects in animal models related to opioid abuse: Drug discrimination and drug self-administration. In Opioid receptors and antagonists: From bench to clinic (ed. Dean EJ, Bilsky R, Negus SS), pp. 221-226. Humana, New York. 
S.S. Negus and M.L. Banks

Negus SS, Banks ML. 2011. Making the right choice: Lessons from drug discrimination for research on drug reinforcement and drug self-administration. In Drug discrimination: Applications to medicinal chemistry and drug studies (ed. Glennon R, Young R), pp. 361-388. Wiley, Hoboken, NJ.

Negus SS, Rice KC. 2009. Mechanisms of withdrawal-associated increases in heroin self-administration: Pharmacologic modulation of heroin vs food choice in heroindependent rhesus monkeys. Neuropsychopharmacology 34: 899-911.

Negus SS, Woods JH. 1995. Reinforcing effects, discriminative stimulus effects, and physical dependence liability of buprenorphine. In Buprenorphine: Combatting drugabuse with a unique opioid (ed. Cowan A, Lewis JW), pp. 71-101. Wiley-Liss, New York.

O'Connor EC, Chapman K, Butler P, Mead AN. 2011. The predictive validity of the rat self-administration model for abuse liability. Neurosci Biobehav Rev 35: 912-938.

Raghavendra V, Tanga FY, DeLeo JA. 2003. Attenuation of morphine tolerance, withdrawal-induced hyperalgesia, and associated spinal inflammatory immune responses by propentofylline in rats. Neuropsychopharmacology 29: 327-334.

Ramesh D, Ross GR, Schlosburg JE, Owens RA, Abdullah RA, Kinsey SG, Long JZ, Nomura DK, Sim-Selley LJ, Cravatt BF, et al. 2011. Blockade of endocannabinoid hydrolytic enzymes attenuates precipitated opioid withdrawal symptoms in mice. J Pharmacol Exp Ther 339: 173-185.

SAMHSA (Substance Abuse and Mental Health Services Administration). 2011. Results from the 2010 national survey on drug use and health. Rockville, MD.

Sell SL, France CP. 2002. Cocaine and amphetamine attenuate the discriminative stimulus effects of naltrexone in opioid-dependent rhesus monkeys. J Pharmacol Exp Ther 301: 1103-1110.

Sevarino K, Kosten T. 2007. Naltrexone for initiation and maintenance of opiate abstinence. In Opioid receptors and antagonists: From bench to clinic (ed. Dean R, Bilsky EJ, Negus SS). Humana, New York.

Shahidi S, Hasanein P. 2011. Behavioral effects of fatty acid amide hydrolase inhibition on morphine withdrawal symptoms. Brain Res Bull 86: 118-122.
Song P, Zhao Z-Q. 2001. The involvement of glial cells in the development of morphine tolerance. Neurosci Res 39: 281-286.

Spragg SDS. 1940. Morphine addiction in chimpanzees. Comp Psychol Mono 15: 5-132.

Sullivan M, Vosburg S, Comer S. 2006. Depot naltrexone: Antagonism of the reinforcing, subjective, and physiological effects of heroin. Psychopharmacology 189: 37-46.

Tawfik VL, LaCroix-Fralish ML, Nutile-McMenemy N, DeLeo JA. 2005. Transcriptional and translational regulation of glial activation by morphine in a rodent model of neuropathic pain. J Pharmacol Exp Ther 313: 1239-1247.

Thompson T, Schuster CR. 1964. Morphine self-administration, food-reinforced, and avoidance behaviors in rhesus monkeys. Psychopharmacologia 5: 87-94.

Vela G, Ruiz-gayo M, Fuentes JA. 1995. Anandamide decreases naloxone-precipitated withdrawal signs in mice chronically treated with morphine. Neuropharmacology 34: 665-668.

Viganò D, Valenti M, Grazia Cascio M, Di Marzo V, Parolaro $\mathrm{D}$, Rubino T. 2004. Changes in endocannabinoid levels in a rat model of behavioural sensitization to morphine. Eur J Neurosci 20: 1849-1857.

Watkins LR, Hutchinson MR, Rice KC, Maier SF. 2009. The "toll" of opioid-induced glial activation: Improving the clinical efficacy of opioids by targeting glia. Trends Pharmacol Sci 30: 581-591.

Wee S, Koob GF. 2010. The role of the dynorphin-к opioid system in the reinforcing effects of drugs of abuse. Psychopharmacology 210: 121-135.

Wurster RM, Griffiths RR, Findley JD, Brady JV. 1977. Reduction of heroin self-administration in baboons by manipulation of behavioral and pharmacological conditions. Pharmacol Biochem Behav 7: 519-528.

Yamaguchi T, Hagiwara Y, Tanaka H, Sugiura T, Waku K, Shoyama Y, Watanabe S, Yamamoto T. 2001. Endogenous cannabinoid, 2-arachidonoylglycerol, attenuates naloxone-precipitated withdrawal signs in morphine-dependent mice. Brain Res 909: 121-126.

Yanagita T. 1978. Drug dependence studies in laboratory animals. NIDA Res Monogr 19: 179-190.

Young AM, Herling S. 1986. Drugs as reinforcers: Studies in laboratory animals. In Behavioral analysis of drug dependence (ed. Goldberg SR, Stolerman IP), pp. 9-67. Academic, Orlando, FL. 


\section{$\&_{\mathrm{CSH}}^{\infty} \&$ Cold Spring Harbor

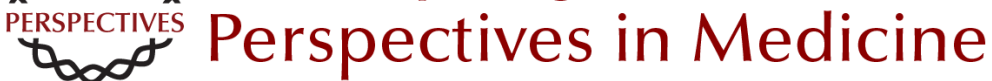

\section{Medications Development for Opioid Abuse}

S. Stevens Negus and Matthew L. Banks

Cold Spring Harb Perspect Med 2013; doi: 10.1101/cshperspect.a012104 originally published online November 1, 2012

\section{Subject Collection Addiction}

Developments from Bulk Optogenetics to Single-Cell Strategies to Dissect the Neural Circuits that Underlie Aberrant Motivational States Jose Rodriguez-Romaguera, Vijay M.K. Namboodiri, Marcus L. Basiri, et al.

Consequences of Parental Opioid Exposure on Neurophysiology, Behavior, and Health in the Next Generations

Fair M. Vassoler and Mathieu E. Wimmer

Animal Models of the Behavioral Symptoms of Substance Use Disorders Louk J.M.J. Vanderschuren and Serge H. Ahmed

Translational Research in Nicotine Addiction Miranda L. Fisher, James R. Pauly, Brett Froeliger, et al.

Neonatal Opioid Withdrawal Syndrome (NOWS): A Transgenerational Echo of the Opioid Crisis Andrew E. Weller, Richard C. Crist, Benjamin C. Reiner, et al.

Impairment of Synaptic Plasticity by Cannabis, $\Delta^{\mathbf{9}}$ -THC, and Synthetic Cannabinoids Alexander F. Hoffman, Eun-Kyung Hwang and Carl R. Lupica

Drug-Evoked Synaptic Plasticity of Excitatory Transmission in the Ventral Tegmental Area Camilla Bellone, Michael Loureiro and Christian Lüscher

Opioid-Induced Molecular and Cellular Plasticity of Ventral Tegmental Area Dopamine Neurons Marie A. Doyle and Michelle S. Mazei-Robison
The Persistent Challenge of Developing Addiction Pharmacotherapies

Sarah E. Swinford-Jackson, Charles P. O'Brien,

Paul J. Kenny, et al.

Opioid Modulation of the Gut-Brain Axis in Opioid-Associated Comorbidities

Li Zhang and Sabita Roy

Epigenetics of Drug Addiction Andrew F. Stewart, Sasha L. Fulton and lan Maze

Genetic Vulnerability to Opioid Addiction Brian Reed and Mary Jeanne Kreek

Glutamatergic Systems and Memory Mechanisms

Underlying Opioid Addiction Jasper A. Heinsbroek, Taco J. De Vries and Jamie Peters

Mechanisms of Nicotine Addiction Marina R. Picciotto and Paul J. Kenny

Neural Substrates and Circuits of Drug Addiction Matthew W. Feltenstein, Ronald E. See and Rita A. Fuchs

The Role of the Central Amygdala in Alcohol Dependence Marisa Roberto, Dean Kirson and Sophia Khom

For additional articles in this collection, see http://perspectivesinmedicine.cshlp.org/cgi/collection/ 